\title{
Interaction Model of Government and Public Corporations in a Market Economy
}

\author{
Anna V. Babikova \\ Nikolay N. Lyabakh \\ Anna Yu. Fedotova \\ Anna V. Khanina \\ Southern Federal University, Russian Federation \\ Email:Kri81@mail.ru
}

\section{Doi:10.5901/mjss.2015.v6n3s5p49}

\begin{abstract}
The article is devoted to the current issues on industrial state corporations in high-tech sector engaged in large-scale projects of economy modernization. Lack of formalized procedures for the interaction of public corporations, state authorities and other participants of market relations can hinder the implementation of a significant potential in science and technology possessed by public corporations. This paper considers the possibility of modeling the relationship between the state and public corporations based on the procedures of the theory of active systems, which enables us to propose an adequate model of the interaction of agents in the system, taking into account the uncertainties. Proposed mathematical model of interactions between government bodies and public corporations is based on the theory of contracts and formal control procedures. It enables to increase the efficiency of interactions by removing restrictions that are required in optimization of interaction problems.
\end{abstract}

Keywords: public corporations, government regulation, active systems theory, contract theory

\section{Introduction}

At the present stage of economic development the leading role in global industrial production belongs to large industrial corporations. Globalization, new technologies that form an innovative economy, leads to the fact that the competitive development of industrial companies depends on their ability to adapt to new conditions. According to the studies on the formation and development of large business enterprises (Dementev, 2011; Becattini et al., 2010), we can highlight certain stages in the formation of corporations, which are characterized by institutional and economic specifics and unique national features. Results of the first stage - the privatization stage in 1987 - 1991, were the first holding structures in Russia, which were not focused on economic or production effects, but rather on acquisition of control over a portion of national state-owned assets. The second stage is mass privatization of $1992-1994$. It was slightly different from previous attempts to create a viable structure, however, the problems of the industrial sector of the economy remained unresolved. The redistribution of the share capital in 1994 - 1996 has not made a significant qualitative changes in existing corporate sector. After the adoption of the law "On joint stock companies" in the period of 1996 1998, there has been some reorganization of enterprises. There was a shift to procedural technologies for corporate control. After 1998, the generally favorable conditions for industrial enterprises were formed, being a result of government regulations aimed at stabilizing the economy after the devaluation of the ruble. The period of $1999-2000$ was marked with an increase in industrial production due to favorable market conditions, but the intensity of industrial production began to decline already in 200 . During this period, the active transformation processes of the corporate sector received a tendency to decrease. In the period of $2006-2007$, significantly increased the proportion of state involvement in the corporate sector of the national economy. The largest number of public corporations was created in this period. For the implementation of public policy development and modernization of the high-tech industry sectors a number of public industrial corporations was established, such as Rusnano, Rosatom and Rostec, whose main objective is the development of strategic industries.

Russian Corporation of Nanotechnologies (Rusnano) was established in 2007 to implement projects for the development of advanced nanotechnology and nano-industry. Nanotechnology today an important part of the high-tech sector, funded by the state. Since 2007, Rusnano started funding 100 projects, including 93 industrial projects and seven 
investment funds for nanotechnology. In 2010, 44 projects were approved by the Corporation, with a total funding of 146 billion rubles, 47.1 billion is the co-financing of Rusnano. In 2011, according to the government order dated by $17^{\text {th }}$ of November 2010, the Russian Nanotechnology Corporation was re-registered as an open joint-stock company "Rusnano", which is the successor to the state corporation with all rights and duties. In 2011, 34 project companies established with the financial participation of Rusnano received the proceeds from the sale of nanotechnology products in the amount of more than 11 billion rubles. According to Rosstat, 384 companies and organizations produced the nanotechnology products in 2012. By 2015, the annual volume of production by the project companies of Rusnano must reach 300 billion rubles, and the total volume of all Russian nanotechnology industry - 900 billion rubles.

The purpose of the Rostec Corporation is to promote the development and manufacture of high-tech products through investments in the industry. In 2010, the volume of work performed in the civil industry was 11,964.2 mln. rubles. Corporation performs actions on the implementation of programs for the development of the military-industrial complex. A number of relevant industries have achieved a significant growth by 2013. For example, the volume of industrial production of radio electronics, being the sphere of Rostec, increased by $14.3 \%$ compared with 2012. In 2013, two major projects were launched in a very important industry sectors - mining of rare earth metals and the production of composite materials, in both of which Rostec plays an active role.

The main objective of the Rosatom Corporation is to provide electricity to the country's economy, products and services of nuclear power complex, the creation of innovative nuclear technologies and their use in various sectors of the economy. In 2010, the volume of investment programs amounted to $220,423.2 \mathrm{mln}$. rubles, mainly in the construction of power. As of the beginning of 2014, Rosatom incorporated more than 360 organizations of various organizational and legal forms. As a result of changes in the period from 2012 to 2014, Rosatom included several previously independent engineering companies. As part of the innovation policy, this state corporation is one of the customers of the Federal Target Program "Nuclear Power of New Generation in 2010 - 2015s and up to 2020". It also takes part in a project for Modernization and Technological Development of the Russian Economy.

Government intervention in the economy caused by the desire to alleviate the inefficiencies associated with the functioning of the market economy. Namely, the market does not automatically solve all economic problems of the country and the winner of the market competition is not always the best. This required a theoretical rethinking of the economic mechanism of the state. As a rule, market planning and business management methods are opposed to each other (Dementev, 2011). Meanwhile, the practice shows the need to combine the activities of the state in these two paradigms.

\section{Mechanism of State Regulation of the Industrial Sector}

Nowadays, the development of new sectors of the innovation economy is accompanied by a number of problems in the formation of a system of measures aimed to implement technological modernization of industry. The solution of these problems determines the need for the formation of such forms and institutions of implementing state policy on industrial development and innovation policy that will provide increasing competitiveness of the Russian economy, as well as the development of basic and related priority industries, increase economic growth. As international experience shows, public corporations are created in industry of different countries in order to accelerate technological development or overcome crisis. Authors suggest, that this corporations are the institutions of implementation of the state industrial policy. Public corporations have considerable potential for innovation, composing of industrial enterprises and research institutes. The presence of stable economic relations, certain strategic goals, objectives, directions and principles of consolidation of intellectual and industrial resources within public corporations enables them to implement government programs of technological modernization of the industry.

It can be argued that, despite the presence of significant innovation potential of domestic enterprises in the country's economy, there still remains the predominance in the share of extractive industries and the low competitiveness of enterprises in world markets of high-tech products. The lack of investment is not the only obstacle to the innovative development of the industrial sector of the economy. By carrying out research and development, having received the results of intellectual activities, enterprises are faced with the problem of commercialization of new technologies. The creation of public corporations in industries follows a targeted installation, which is to promote the development and export of high-tech nanotechnology developments, creation of new competitive industries and economic security. All of which is primarily aimed at ensuring national sustainable economic growth. Public corporations that are currently active in the country's economy operate on the implementation of public policies aimed at the development and modernization of the industry in their respective industries, which allows us to consider them as organizational - institutional mechanism of state regulation of the industrial sector. 
Nevertheless, the development of high-tech industries via public investment in conjunction with the principles of corporate governance and market mechanisms has not yet delivered the expected results, since not all public corporations demonstrate the effect correlated with investments. The purpose of public corporations is to overcome the poor quality of the administrative system, its primary focus on solving problems, to solve the problems in the formation and implementation of measures for the development of new sectors of the economy, to contribute the resolution of longterm issues.

Development and implementation of formalized procedures for the analysis, identification, planning and management of the public corporations can bridge some of these problems and alleviate a number of other issues. Management theory of organizational systems (Intriligator, 2002), optimal control theory (Allen, 1963) currently provide a fairly wide range of economic and mathematical methods in this respect. However, their options are limited due to the complexity (high dimension, uncertainty) of operating environment of the public corporations, and therefore, in this paper we propose to focus on the procedures of the active systems theory and contract theory (Salanié,1997; Bolton \& Dewatripont, 2005; Burkov \& Novikov, 1999). This theories provide self-organization which reduces the negative impact of subjectivity of the decision maker on the one hand and reduces the a priori uncertainty on the other.

\section{Application of the Active Systems and Contract Theories in Practice}

Contract theory studies the theoretical-game schemes of interaction between the governing body (i.e. the state) as the center and the managed entity (public corporation), called an agent, operating in the conditions of the probabilistic uncertainty. Further assume that the agent has $n$ number of options at his disposal: $x_{i}, i=1, \ldots, n$ which respectively lead to the $n$ results with a certain probability: $y_{i}, i=1, \ldots, n$. That is the result, in general, is a random event that determines the uncertainty of the operational environment. The assumptions include the following hypotheses that reflect the true state of relations between the state (state authorities) and the public corporation:

- Actions of an agent are not observed by the center, which is not aware of results;

- Agent is informed about the environment at the level of the distribution law (state of probabilities);

- Agent as well as the government make a decision to maximize their gains from the interaction;

- The objective function public corporation are gains, which is identified with the difference between income and incentives. Other advantages (disadvantages) of the public corporation are not considered in this model.

For convenience of research, we consider the mathematical formalism of decision-making for the case of $n=2$ (see Burkov \& Novikov, 1999). Next, using the principle of dichotomy, this result can be extended to any number $n>2$. To this end, all but one of the options of solution are combined in one unit. Thus, the case $n=2$. Further, for the combined $n$ -1 variants procedure is repeated until all individually basic variants of the problem are addressed.

The agent has two possible effects of $X=\left(x_{1}, x_{2}\right)$, which having the probability $p$ lead to two results $y=(y 1, y 2)$. Obviously, the condition is $p>0.5$. While $p=0.5$ is a complete a priori of uncertainty. Matrix of compliance of the action results will as follows:

$$
P=\left(\begin{array}{cc}
p & 1-p \\
1-p & p
\end{array}\right)
$$

Denote the costs of the public corporation for the implementation of the above decision options as $c_{1}$ and $c_{2}$, respectively (for definiteness let $c_{2} \geq c_{1}$ ), and the expected income from the performance of the center of the action of public corporation is $H_{1}$ and $H_{2}$, respectively. We also denote the size of the government stimulus of public corporation activities as $s_{1}$ and $s_{2}$, respectively. In our notation, the objective function of the state (the difference between income and incentives) is

$$
J_{4}=p\left(H_{1}-s_{1}\right)+(1-p)\left(H_{2}-s_{2}\right) \text {. }
$$

The objective function of an agent (the difference between incentives and costs) is expressed by the ratio:

$$
\mathrm{J}_{\mathrm{a}}=p\left(s_{1}-c_{1}\right)+(1-p)\left(s_{2}-c_{2}\right) \text {. }
$$

The task of the center is to assign a system of incentives that would maximize the expected value of its objective function, provided that the action selected by the agent maximizes the expected value of its own objective function (Burkov \& Novikov, 1999). This is the basic idea of the method: to implement market conditions of the functioning of the members while ensuring the state functions for which the public corporation was created.

The task of finding the minimum incentive system that implements the action of an agent $x_{1}$, is as follows:

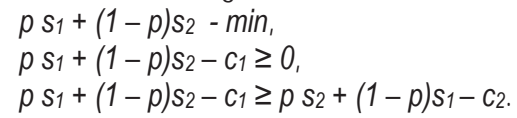

Equation (4) reflects the requirement of minimizing the cost of the state to stimulus, the expression (5) suggests 
that the average amount received by the agent shall not be less than zero, and finally, (6) is made a requirement of incentive consistency: the average amount received by an agent should not be less than the loss of a center.

Problem (4) - (6) is linear programming problem. By virtue of the fact that the dimension of the problem equals two, it can easily be solved graphically. Figure 1 reflects the restrictions (5) and (6) as straight lines, the given are is hatched. Direction of the hatching coincides with the direction of minimization vector defined by the relation (4).

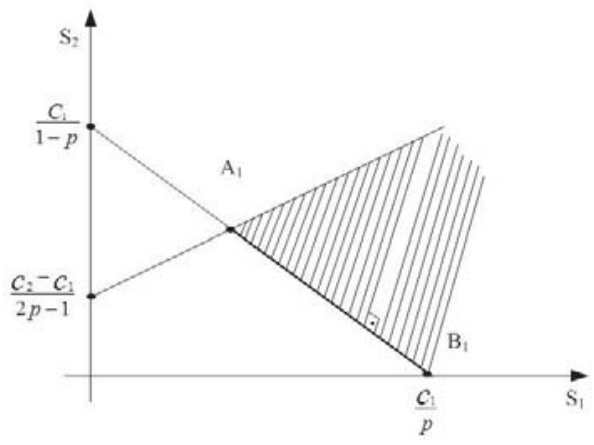

Figure 1. Implementation of the agent action of the center $x_{1}$

Thus, the admissible domain of solutions coincides with the segment $A_{1} B_{1}$. Focusing on demand of maximization of utility functions (2) and (3), $A_{1}$ is selected as the decision point. It is easy to check that it is characterized by values:

$s_{1}=\left(p c_{1}+(1-p) c_{2}\right) /(2 p-1)$,

$s_{2}=\left(p c_{2}+(1-p) c_{1}\right) /(2 p-1)$.

Expected costs of the center (the mathematical expectation of a random variable $C$ ) equals $\mathrm{s} 1$.

Suppose that the center wants to implement the agent action of $x_{2}$. Arguing similarly, we obtain Figure 2, which is also the relations (7) and (8) with a mathematical expectation of the costs being equal to $\mathrm{s}_{2}$.

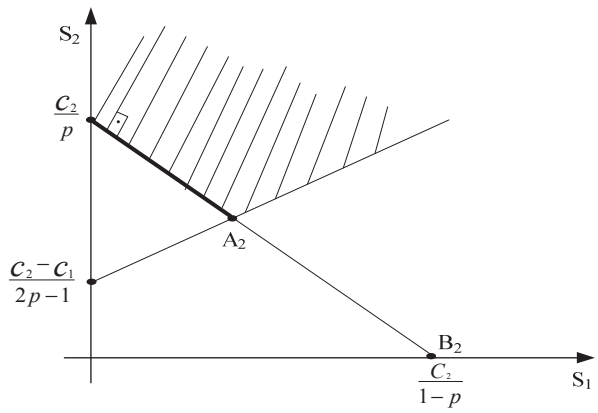

Figure 2. Implementation of the agent action of the center $x_{2}$

We shall investigate the previously introduced limitations to simplify the model.

A) "Actions of an agent are not observed by the center, which is not aware of results". If this restriction is removed, enabling the observability of the operation of the public corporation (i.e. creating a special monitoring system), it will simplify the mathematical formulation of the problem. It will cease to be stochastic and turn to be deterministic problem solving.

B) "Agent is informed about the environment at the level of the distribution law (state of probabilities)". This restriction is feasible, if the law of the distribution is known a priori or can be built according to the statistics. It is rather difficult to perform to perform this restriction. In this case, a "subjective probability" is proposed membership function of a fuzzy set, replacing the distribution probability (see Katsko \& Krepyshev, 2010). It can be synthesized by experts on the basis of experience and intuition.

C) "Agent as well as the government make a decision to maximize their gains from the interaction" - the natural 
assumption that does not require any comment.

D) "The objective function public corporation are gains, which is identified with the difference between income and incentives. Other advantages (disadvantages) of the public corporation are not considered in this model". It is also a hard restriction that can be ceased if advantages and disadvantages of the organization of the public corporation to be evaluated in monetary units, and added to income $\mathrm{H}_{\mathrm{i}}$ (in the first case) or to the costs $\mathrm{Ci}_{\mathrm{i}}$ (in the second).

\section{Conclusion}

The study revealed some problems in activities of public corporations. Closeness of public corporations is not conducive to objective control, calculation of adequate models of operation, and, therefore, improvement of their activity. Available data do not reflect any significant trends (correlation of factors and indicators of development, trends, cycling), which is always present in the activities of economic entities. The complexity of the operational environment of state corporations, namely the high dimensionality and uncertainty, their limited opportunities have predetermined the procedures of the active systems theory used in this paper. They provide self-organization that reduces the negative impact of subjectivity of the decision maker on the one hand, and reduces the a priori uncertainty on the other.

The proposed mathematical model of interaction between the state (i.e. government authorities) and the public corporations introduces the latter in market relations and increases their efficiency in the functioning of a market economy. The proposed approach removes a number of restrictions imposed by the classical formulation of the problem of optimization of interactions (e.g. low dimensionality of the problem, the statistical uncertainty of intangible advantages and disadvantages of public corporations' actions). In the absence of empirical data to the extent necessary to build the model, one can use relevant tools to obtain expert data. The experts, based on common sense and personal experience using the theory of fuzzy sets, set the calculated values. In order to increase the statistical validity it is required to implement an option of several experts and the option of one expert. The lack of proper external control over the activities of public corporations is proposed to compensate by the introduction of formal procedures, which formally regulate the interactions between the parties (i.e. the state and the public corporations), as well as the transparency of corporate activities.

\section{References}

Allen, R. (1963). Mathematical economics. Moscow

Becattini, G., Bellandi, M., \& Propris, L. (2010). Critical Nodes and Contemporary Reflections on Industrial Districts. Regional. Proceedings of the regional studies association annual international conference "Responses and Global Shifts: actors, institutions and organizations". [Online] Available: http://www.regional-studies-assoc.ac.uk/events/2010/may-pecs/papers/Becattini.pdf (February 10, 2015).

Bolton, P., \& Dewatripont, M. (2005). Contract Theory. Cambridge, Mass. \& London, England: MIT Press.

Burkov, V.N., \& Novikov, D.A. (1999). Theory of active systems: status and prospects. Moscow.

Dementev, V.E. (2011). Public corporations, especially foreign experience and advice for Russia. Management and Business Administration, 3, 8-19.

Intriligator, M. (2002). Mathematical methods of optimization and economic theory. Moscow: Iris-Press.

Katsko, I.A., \& Krepyshev, D.A. (2010). Stages of Applied System Studies - the basis of decision-making process of intellectualization. Herald of Rostov State University of Railways, 6 (39).

Salanié, B. (1997). The Economics of Contracts: A Primer. Cambridge, Mass. \& London, England: MIT Press. 
